\title{
Repositórios no contexto da EaD: O Banco Internacional de Objetos Educacionais
}

Seminário Repositórios Institucionais e de Objetos Virtuais de Aprendizagem

Florianópolis, Novembro - 2009

Anna Christina de Azevedo Nascimento

Secretaria de Ed a Distância - Ministério da Educação 


\section{O que é um repositório?}

Repositórios digitais servem para armazenar conteúdos que podem ser pesquisados por meio de busca e acessados para reutilização.

Os mecanismos de identificação, armazenageme acesso são partes importantes de um repositório.

Diferentes níveis de acesso - acesso para visualização, ou de visualização e download. Ou visualização, dounload, e contribuição de material 


\section{O Repositório educacional}

Qualquer recurso digital com aplicação na educação pode ser incluído em um repositório educacional.

Tipos de materiais encontrados nos repositórios: software, multimídia, textos, livros eletrônicos, testes, ementas de cursos, cursos, simulações, planos de aula, apresentações, arquivos de áudio e vídeo, e outros. 


\section{Objetos de aprendizagem}

Recursos educacionais digitais desenvolvidos com certos padrões para permitir reutilização em vários contextos educacionais, e eles são armazenados em repositórios educacionais. 
Objetos de aprendizagem precisam ser catalogados para permitir que os usuários os encontrem facilmente nos repositórios. 
O compartilhamento gratuito de recursos pode reduzir bastante $\mathrm{o}$ tempo que os professores gastam para pesquisar e obter permissão de uso para incluí-los em seus materiais de ensino.
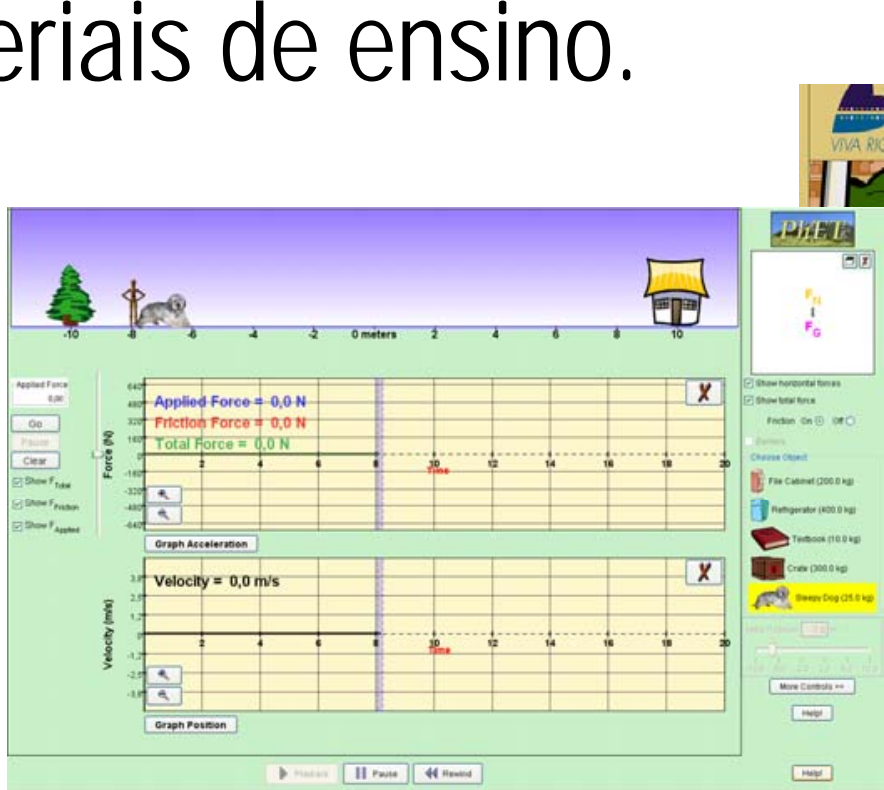
Os repositórios educacionais que oferecem recursos digitais no formato de animações, simulações e vídeos estão beneficiando alunos a compreenderem fenômenos científicos complexos, mesmo sem ter acesso a laboratórios de alta tecnologia. 
Os recursos, nos formatos de áudio, vídeo, imagens e animações atendem a educação infantil, básica, profissionalizante e superior, nas diversas áreas do conhecimento.
Banco Internacional de Objetos Educacionais

Banco Internacional de Objetos Educacionais

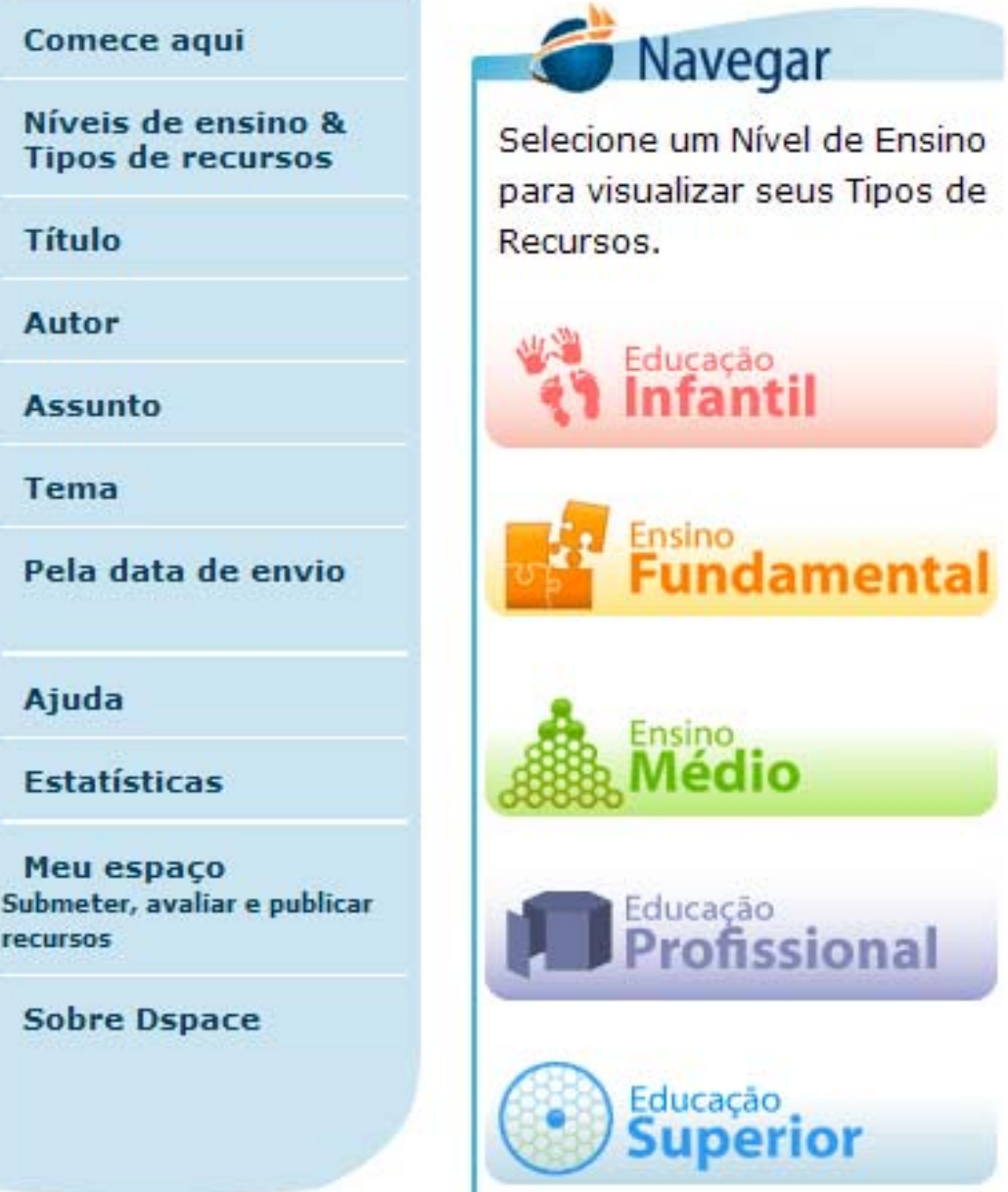




\section{Benefícios esperados do Banco}

- Enriquecer o acervo de recursos educacionais disponíveis

- Aumentar a demanda por conteúdos de qualidade, através de controle de qualidade e feedback

- Economia de tempo e investimento através da reutilização dos recursos 
Para apoiar os professores, e complementar a oferta do

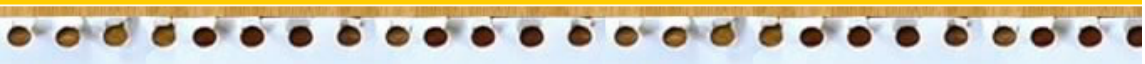
Partal da Profiessar repositório foi implementado um portal.

O objetivo é estimular a construção de uma comunidade de professores para compartilhar e reutilizar os

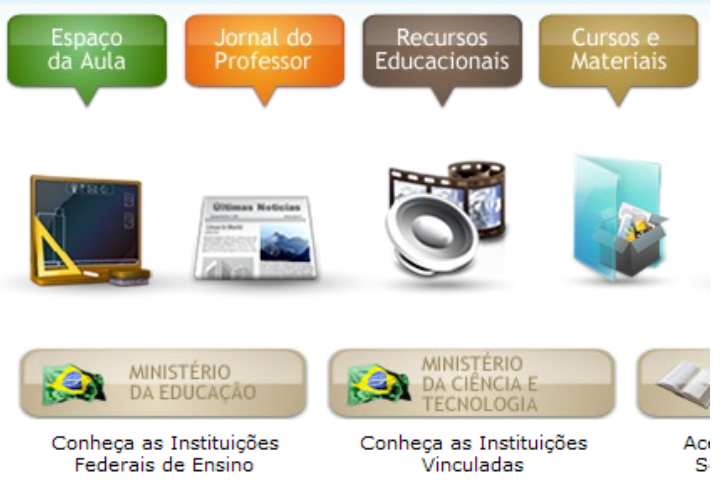
recursos educacionais. 


\section{Um repositório de acesso aberto}

Professores de qualquer parte do mundo poderão acessar os recursos educacionais em seus idiomas originais, incluindo o português do Brasil.

Os recursos poderão ser traduzidos para qualquer outra língua e publicados novamente no Banco Internacional, gerando assim uma escalabilidade.

Nesse modelo, todos cooperam e todos são beneficiados. 
Totalmente desenvolvido em software livre, o BIOE facilita a oferta de recursos educacionais igualmente livres, representando assim um importante instrumento de divulgação e disseminação do uso de plataformas abertas. 


\section{Desenvolvimento do BIOE}

- Escolha de plataforma D-Space, recurso aberto e gratuito

- Recrutamento de equipes de professores e alunos nas universidades para identificar na web recursos educacionais de qualidade

- Obtenção de cessão de direitos para publicação e uso educacional dos materiais

- Catalogação dos recursos no Banco 


\section{Duas formas de alimentação do Banco}

13 instituições foram selecionadas em 2007 num edital público para produzir recursos digitais multimídia, num investimento de 55 milhões

São 9 equipes de diferentes universidades que pesquisam e catalogam recursos - 350 pessoas 
Por que trabalhar com as universidades?

Enriquecimento da formação de futuros docentes, e bibliotecarios por meio das atividades de pesquisa, avaliação e catalogação de recurso para o BIOE. 
A construção de uma rede colaborativa para alimentar o Banco Internacional e a integração com outros repositórios de recursos digitais favorecerá o surgimento de um volume significativo de materiais, que poderá ter um grande impacto nas inovações das práticas educativas brasileiras. 


\section{Propriedade intelectual}

Instituições e autores diversos devem entregar a cessão de direitos de seus materiais antes que eles possam ser publicados no repositório e no portal.

Apesar de adotarmos a licença do creative commons, cada autor pode determinar condições específicas para o material que criou.

\section{cc) creative


Todos os recursos do portal são de acesso aberto e gratuito.

Porém a preocupação do MEC é de que esses recursos sejam de alta qualidade educacional 


\section{Qualidade}

Para garantir qualidade é essencial que os recursos passem por uma avaliação de especialistas antes de serem publicados no Banco

Os recursos excluídos retornam com feedback para permitir revisão e melhoria de qualidade 
A avaliação dos recursos é realizada por um comitê de professores de diferentes áreas, que acessam o sistema do repositório e recomendam a exclusão ou publicação dos recursos

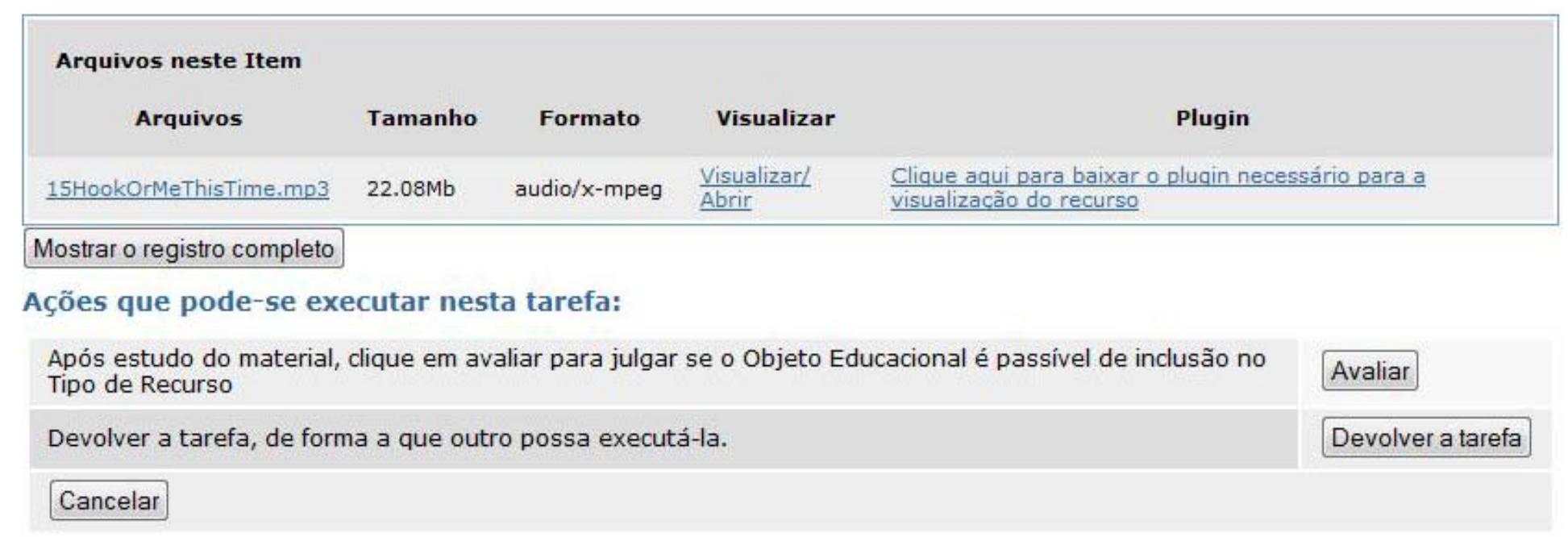


Perto de 800.000 pessoas já acessaram o repositório desde seu lançamento em junho de 2008

144 países já acessaram o repositório

7.771 objetos multimídia disponíveis no repositório 
Países que cederam recursos para o BIOE: Argentina, Ilha Bovet, Canadá, China, Colômbia, Alemanha, Espanha, França, Inglaterra, México, Nova Zelândia, Peru, Porto Rico, Portugal, Estados Unidos, Uruguai

Os 10 países que mais acessam o Banco: Brasil, Portugal, Estados Unidos, México, Angola, Moçambique, Colômbia, Espanha, Peru Argentina

Os 10 estados brasileiros que mais acessam o Banco: São Paulo, Rio de Janeiro, Brasília, Belo Horizonte, Salvador, Curitiba, Recife, Goiânia, Fortaleza e Porto Alegre. 


\section{Futuras implementações}

Possibilidade dos usuários submeterem seus recursos

Usuários poderão criar suas listas de favoritos e coleções

Interoperabilidade entre outros sistemas do MEC - Portal, Domínio publico, e-proinfo 
Principais questões que envolvem o uso de recursos de repositórios

- Confiança na qualidade dos recursos

- Direitos autorais

- Relutância de autores em oferecer materiais de gratuitamente

- Vocabulário utilizado para criação de metadados nem sempre de fácil compreensão para o usuário

- Pesquisas sobre os progressos nas práticas de utilização dos repositórios e recursos 


\section{Obrigada!}

Contato

Anna Christina Aun de Azevedo Nascimento

Banco Internacional de Objetos Educacionais

hittp://objetoseducacionais2. mec.gov.br/

Secretaria de Educação a Distância

Ministério da Educação

(55)(61) 2022-9557

annanacimento@mec.gov.br 